\title{
Rock Magnetic Properties of the Arunta Block, Central Australia, and Their Implication for the Interpretation of Long-Wavelength Magnetic Anomalies
}

\author{
PAUL R. KELSO ${ }^{1}$, SUBIR K. BANERJEE, AND CHRISTIAN TEYSSIER
}

Institute for Rock Magnetism, Department of Geology and Geophysics, University of Minnesota, Minneapolis

\begin{abstract}
Rock magnetic and petrologic studies of a suite of deep crustal rocks from the Arunta Block of Central Australia reveal that the granulite grade rocks are in general much more magnetic than the amphibolite grade samples irrespective of bulk rock composition. The dominant magnetic mineral in all samples is relatively pure magnetite as determined from thermomagnetic and electron microprobe analysis. The bulk magnetic properties are typical of pseudo-single-domain to multidomain size material. The samples from our study have very large remanences compared to previous crustal magnetic studies, with the granulites having a median natural remanent magnetization of $4.1 \mathrm{~A} / \mathrm{m}$ and Koenigsberger ratio of 7.2. These remanences are relatively resistant to thermal demagnetization, with nearly $50 \%$ of the magnetization remaining after $400^{\circ} \mathrm{C}$ demagnetization. Thus remanence may contribute significantly to the observed magnetic anomalies, including long-wavelength magnetic anomalies, the source of which resides at depth and therefore at elevated temperature, where a thermoviscous remanent magnetization along the present-day field is likely to dominate. The magnetic susceptibilities of the samples are only capable of producing a magnetization of less than $1 \mathrm{~A} / \mathrm{m}$ in the $0.05 \mathrm{mT}$ present-day field of Central Australia. Susceptibility is nearly constant with temperature to within $30^{\circ} \mathrm{C}$ of the Curie temperature where it decreases rapidly, i.e., there is no significant Hopkinson peak. The granulite samples from this study have magnetizations, both remanent and induced components, that are large enough to account for most long-wavelength magnetic anomalies if they are juxtaposed with relatively nonmagnetic rocks, similar to the high-grade rocks in the Canadian Shield.
\end{abstract}

\section{INTRODUCTION}

\section{Background Information}

There has been an increasing interest in long-wavelength magnetic anomalies in recent years, in great part due to the magnetic data collected by the POGO and Magsat satellites. These data sets have provided many insights into the different sources contributing to the earth's magnetic field, from core processes to external fields. Of direct interest to this paper is the component of the magnetic field due to the continental lithosphere. Attempts to identify and model the lithospheric components of magnetization (for reviews, see Mayhew et al. [1985]; and Mayhew and LaBrecque [1987]) have resulted in the recognition of widespread long-wavelength $(>100 \mathrm{~km})$ magnetic anomalies over both the continents and the oceanic basins. Modeling the shape and amplitude of these anomalies suggests that their source resides in the lithosphere. The few magnetic studies of mantle material [Wasilewski et al., 1979; Wasilewski and Mayhew, 1982, 1992] have found that the continental mantle is relatively nonmagnetic, as is argued from thermodynamic considerations by Frost and Shive [1986]. Thus most modelers have considered the Moho to be the lower limit for the source of the observed anomalies. Inverse modeling of the anomalies typically shows that contrasts in magnetization of a few $\mathrm{A} / \mathrm{m}$ are necessary assuming the entire continental crust is uniformly magnetic (for reviews, see

\footnotetext{
${ }^{1}$ Now at Department of Computer, Geological and Mathematical Sciences, Lake Superior State University, Sault Ste. Marie, Michigan.

Copyright 1993 by the American Geophysical Union.

Paper number 93JB01158.

0148-0227/93/93JB-01158\$05.00
}

Mayhew and LaBrecque [1987]; and Hahn and Roeser [1989]). The thickness of the magnetic layer in a specific region is also dependent on the geotherm, which can vary widely. Based on thermal considerations only and a $600^{\circ} \mathrm{C}$ Curie temperature (i.e., isotherm), the thickness of the magnetic lithosphere varies from $20 \mathrm{~km}$ to over $60 \mathrm{~km}$ [Frost and Shive, 1986].

However, previous studies of crustal rocks [Schlinger, 1985; Williams et al., 1985; Shive and Fountain, 1988; Wasilewski and Warner, 1988; Toft and Haggerty, 1988] have measured room temperature magnetizations that are much less than those required by calculations from anomaly modeling (for reviews, see Mayhew et al. [1985]; and Hahn and Roeser [1989]), sparking much debate about the source of these anomalies. The magnetic source can be an induced magnetization associated with the magnetic susceptibility of the rocks and/or a remanent magnetization which may include a component of viscous magnetization [Toft and Haggerty, 1986; Mayhew and Johnson, 1987; Thomas, 1987; Shive, 1989; Arkani-Hamed, 1991; Mayhew et al. 1991]. Most previous studies of tectonically uplifted crustal blocks have dealt with generally silicic rock suites [Schlinger, 1985; Williams et al., 1985; Shive and Fountain, 1988] which are probably not representative of middle to lower crustal rocks. Another problem that plagues these studies is reequilibration of phases, including the opaque minerals, during uplift [Wasilewski and Warner, 1988]. As an integral part of any study of crustal rocks, a petrographic analysis must be performed to investigate the effect of retrogressive metamorphism on the measured rock properties. This is especially critical for magnetic properties which can change dramatically with slight changes in the oxygen fugacity, oxide composition, or texture, especially since the magnetic minerals occur as accessories comprising less than a few percent of the total rock volume.

Lower crust specimens also occur in xenolith-bearing igneous rocks, but to date there have been very few studies on 
the magnetic properties of xenoliths [Wasilewski et al., 1979; Wasilewski and Mayhew, 1982, 1992; Toft and Haggerty, 1988]. A major disadvantage of xenolith studies is that they provide only one dimensional sampling. This sampling may not be random, and thus it is often difficult to determine the relative proportion of the different lithologies within the crust. The crustal stratigraphy can only be determined through a source depth distribution profile for the xenoliths calculated from phase equilibria. It has only been through recent advances in the field of geothermobarometry that the depth of the different samples can be determined with sufficient accuracy to reconstruct the geotherm[O'Reilly and Griffin, 1985; Berg et al., 1989]. Again care must be taken to determine whether the oxides equilibrated at peak metamorphism, or during uplift. No study to date has incorporated magnetic properties with detailed pressure-temperature calculations, but this could be a fruitful approach for future work.

We have chosen to study a tectonically exposed crosssection of the Australian continental crust to understand better the magnetic properties of continental crustal rocks, and how these properties may change as a function of depth and temperature within the Earth. The ultimate goal has been to help identify the source of long-wavelength magnetic anomalies. We address this problem through a comprehensive study of laboratory-measured magnetic properties, in situ magnetic susceptibility measurements, and transmitted and reflected light petrographic analysis. This is the first such study of a tectonic section where a major component of the terrane is comprised of mafic granulite, which is often suspected to be the most likely source for long-wavelength magnetic anomalies [e.g., Mayhew et al., 1991]. Our work suggests that granulite-grade rocks are indeed a major contributor to these anomalies. Finally, our results and those from previous studies are briefly reviewed to present an overview of our current understanding of the magnetization of the continental lithosphere.

\section{Geological Setting}

A suite of amphibolite to granulite grade rocks from the Arunta Block of Central Australia (Figure 1) has been studied. This suite was chosen for several reasons: (1) it contains a wide

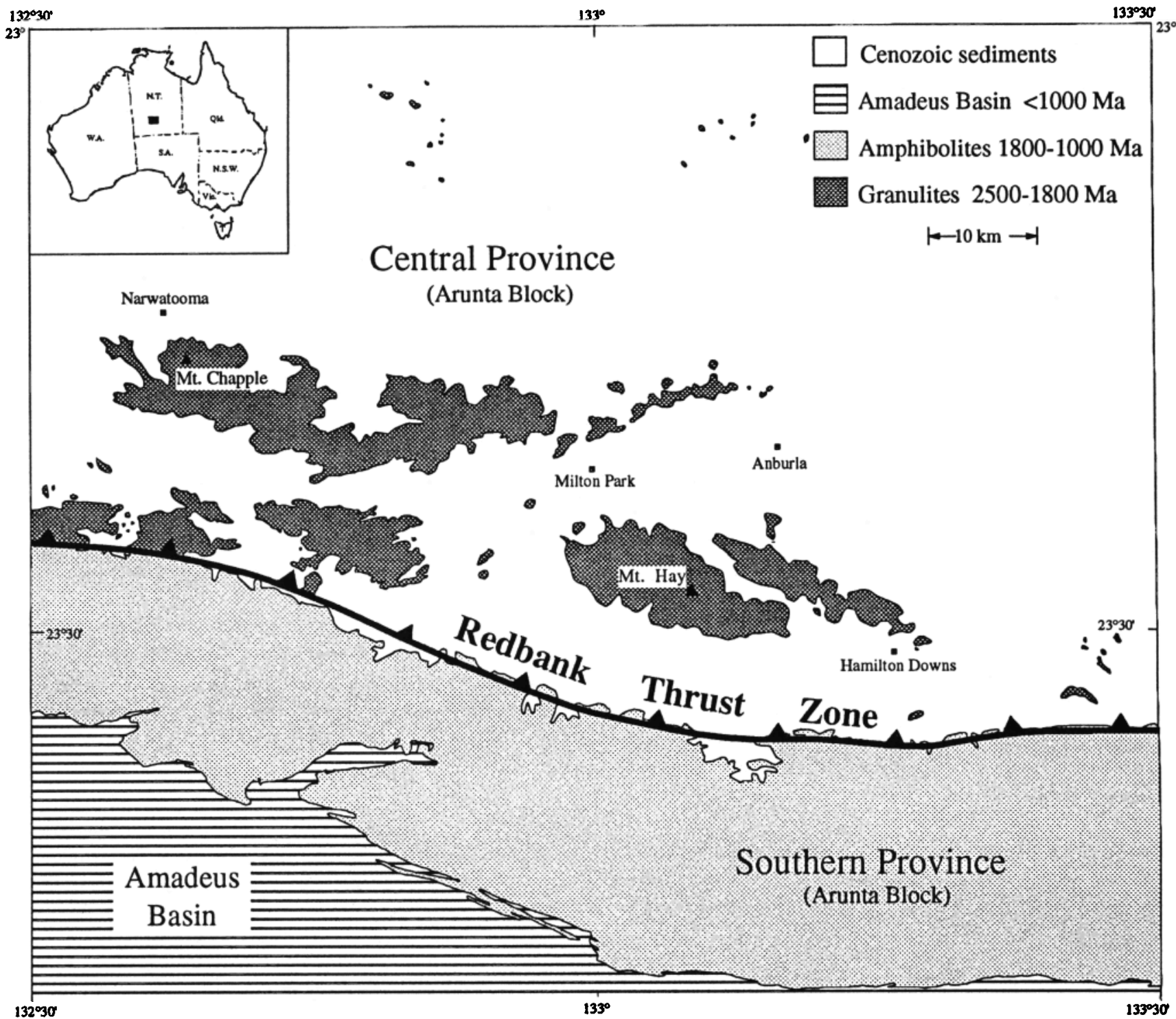

Fig. 1. A generalized geologic map of the study region in the Arunta Block of Central Australin. 
range of compositions but includes a large proportion of mafic rocks; (2) the samples have pristine mineralogies with little or no evidence of retrograde metamorphism; (3) the rocks are well exposed and afford generally easy access; (4) fresh samples can easily be obtained because the weathered layer is generally less than $5 \mathrm{~mm}$ thick; (5) the locale has been the site of several detailed studies over the past decade which include seismic, structural, tectonic, and geochronologic studies [Glikson, 1987a; Teyssier, 1985; Glikson, 1987b; Goleby et al., 1988; Teyssier et al., 1988; Collins and Teyssier, 1989; Shaw and Black, 1991; Black and Shaw, 1992; Shaw et al., 1992].

The metamorphic Arunta Block is exposed north of the Amadeus Basin and is subdivided into Northem, Central, and Southern Provinces based on stratigraphy, metamorphism, and tectonic evolution (Figure 1). This study concentrates on the rocks of the Central Province, but includes some sampling of the Southem Province. The Central Province is characterized as a granulite grade metamorphic terrane with compositions ranging from felsic to mafic [Stewart et al., 1984; Glikson, 1987a; Shaw and Black, 1991]. Peak metamorphism for the Central Province was $8 \pm 1 \mathrm{kbar}(1 \mathrm{kbar}=100 \mathrm{MPa})$ and 700 . $900^{\circ} \mathrm{C}$ [Glikson, 1987a; Shaw, 1987], which occurred during the Late Strangways event at approximately $1700-1800 \mathrm{Ma}$ [Black et al., 1980, 1983; Shaw et al., 1984; Black and Shaw, 1992]. The Southern Provinces experienced a peak metamorphism of amphibolite grade, and rock types mainly include metasediments, metavolcanics, granitoids, and migmatites [Shaw et al., 1984; Stewart et al., 1984]. The peak metamorphism in the Southern Province occurred during the Aileron event at 1600-1700 Ma [Black et al., 1983; Shaw et al., 1984; Black and Shaw, 1992] at pressures of 3-5 kbar and temperatures of $500-600^{\circ} \mathrm{C}$ [Shaw et al., 1984; Shaw, 1987]. Thus, we infer that the Southern and Central Provinces were metamorphosed at depths of approximately 15 and $25 \mathrm{~km}$, respectively, although a more detailed study of how metamorphism varies within or across either province has not been performed.

The dominant structure in the region is the Redbank Thrust Zone (RTZ) that separates the Central and Southem Provinces, and strikes generally east-west. The RTZ maintains a dip of approximately $40^{\circ}$ to a depth of at least $30 \mathrm{~km}$, as imaged in a recent seismic reflection survey [Goleby et al., 1988]. The Moho may be offset across the RTZ [Lambeck et al., 1988; Goleby et al., 1988] although the Moho is poorly defined, as is commonly observed in many Precambrian cratons [Brown et al., 1987]. A large Bouguer gravity anomaly ( $\approx 150 \mathrm{mGals})$ is associated with the RTZ over a distance of approximately 40 $\mathrm{km}$ from the Amadeus Basin to the granulites of the Central Province [Wellman, 1978], and there is also a distinct change in the character of the aeromagnetic anomalies across this zone [Mutton and Shaw, 1979; Glikson, 1987b]. Recent structure and geochronology studies suggest that the RTZ has had a complicated tectonic history, but in general has experienced two main thrusting events, one during the Anmatjira Event at $-1500-1400 \mathrm{Ma}$ and the other during the Alice Springs Orogeny at 400-350 Ma [Collins and Teyssier, 1989; Shaw and Black, 1991]. Deformation during these events has been concentrated along the RTZ allowing relatively passive uplift of the granulite terrane. Therefore the textures and mineralogy of the granulites are generally pristine and have not reequilibrated during uplift (Figure 2). Deformation has occurred along a few discrete, retrograde shear zones within both the Southern and Central Provinces, but this is usually relatively easy to identify in the field and from petrographic observations.

\section{Classification of Rocks}

The rock classification of this study is based on the previous work in the area by Glikson [1987b], as well as our observations in the field and on the microscope. The samples were classified as granulites based on textural characteristics and composition. The granulites exhibit the classic granoblastic texture [Vernon, 1975] and typically contain orthopyroxene, clinopyroxene, plagioclase, magnetite, ilmenite, plus or minus other accessory phases $(<5 \%)$ which may include gamet, potassium feldspar, biotite, homblende, quartz, or sulfides. The granulites were further subdivided into mafic, intermediate and felsic, based on the percentage of ferromagnesian minerals of $>40 \%, 25-40 \%,<25 \%$, respectively. Units that had the above mineralogy, but were compositionally banded on a fine scale $(<5 \mathrm{~cm})$ into ferromagnesian rich and ferromagnesian poor layers, are classified as gneisses, not as granulites. The rocks classified as non-granulites include gneisses, anorthosites, amphibolites, schists, aluminum-silicate bearing units, and calc-silicate bearing units. This separation into granulites and non-granulites was a practical convenience from a magnetic standpoint and is not based on rigorous genetic or petrologic relationships.

Approximately 100 polished thin sections have been examined, in both transmitted and reflected light, from the samples upon which the magnetic properties were measured. Optically, the granulites show no evidence of zoning in either the silicates, including gamet, or the opaques. The opaque minerals have been examined in some detail since they are responsible for the magnetic properties of the samples. The opaque mineralogy is dominated by magnetite and ilmenite with $<10 \%$ being sulfides (pyrite, chalcopyrite, pyrrhotite). The opaques usually occur as discrete grains, intimately associated coarse intergrowths of magnetite-ilmenite (Figures $2 c$ and $2 d$ ), along grain boundaries, and in some cases in microfractures and as rods along plagioclase and pyroxene grain boundaries (Figure $2 b$ ). Hematite-type staining has been observed in a few samples, most often in samples that display evidence of retrograde metamorphism or surficial weathering; but hematite has not been identified as a significant contributor to the magnetic properties of these rocks. Magnetite grains occasionally contain fine lamellae ( $<1 \mu \mathrm{m} \times 1$ to tens of $\mu \mathrm{m}$ ) that are either aligned in one plane (Figures $2 c$ and $2 d$ ), occur along two perpendicular planes, or, in a few cases, along three planes. We have examined the lamellae with both an electron microprobe and a scanning electron microscope with an energy dispersive system (SEM EDS) but could not determine their exact composition because of their small size. The major cation element composition of the lamellae is aluminum plus iron, although the iron in the analysis could come solely from the surrounding magnetite as the beam diameters are larger than the lamellae widths. Aluminum must account for a minimum of $10 \%$ of the lamellae composition. The aluminum cannot be contamination from the polishing compound as the samples for SEM analysis were polished with diamond slurries and were never exposed to any alumina compound. The effect these lamellae may have on the rocks' magnetic properties will be discussed in the section on rock magnetism. 

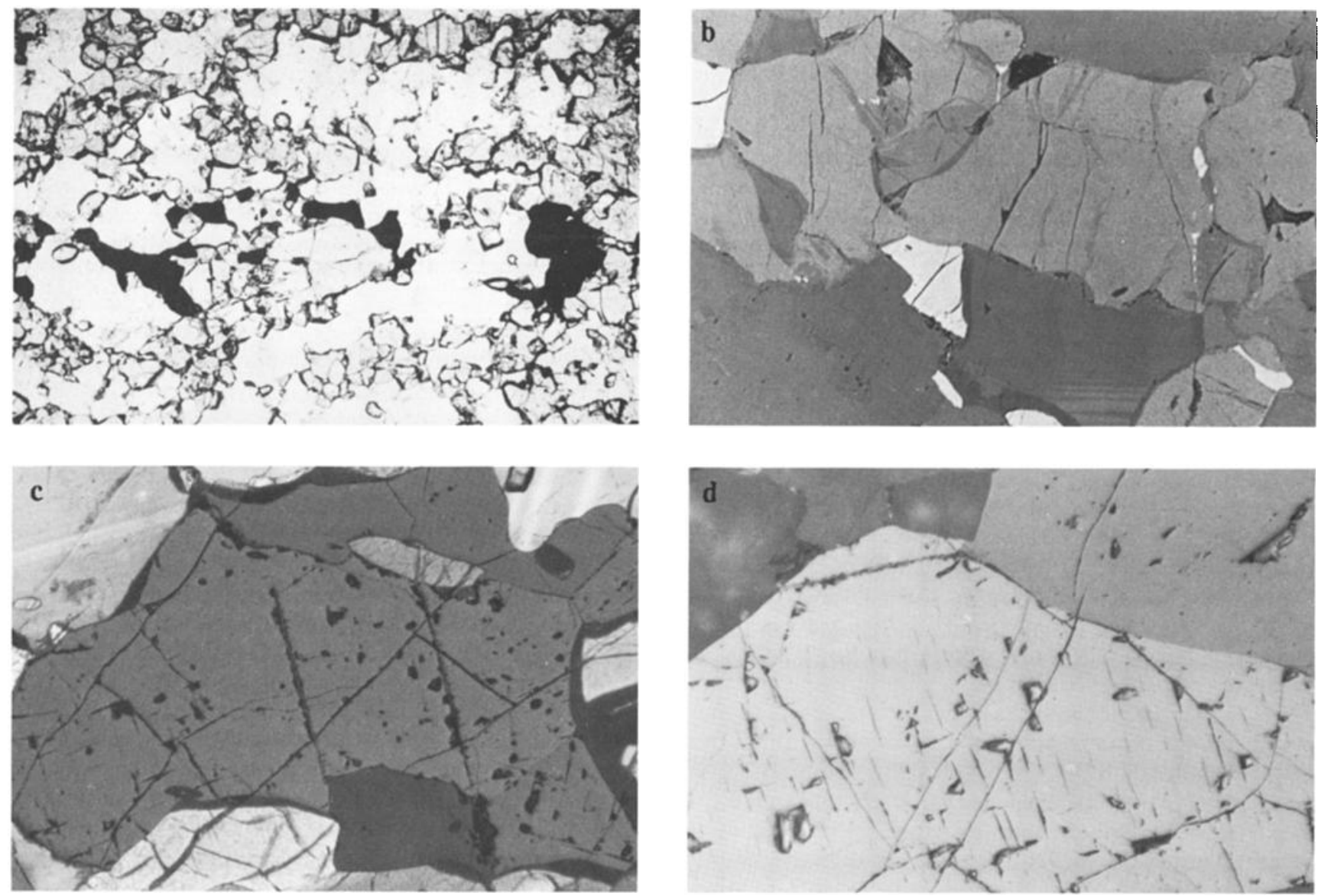

Fig. 2. Photomicrographs of polished thin sections in reflected and transmitted light of representative granulite grade samples. (a) Typical granulite texture of sample 154B4b in transmitted light containing plagioclase, pyroxene, and oxide (long dimension $3 \mathrm{~mm}$ ). (b) Sample 103A4b in reflected light (long dimension $0.62 \mathrm{~mm}$ ). Note wormy oxides along grain boundary in center right and rods in upper right. (c) Sample 246E2a in nearly cross polarized reflected light (long dimension $0.8 \mathrm{~mm}$ ). Note lamellae in right center portion of the magnetite grain. (d) Sample 246E2a in reflected light (long dimension $0.25 \mathrm{~mm}$ ). Note lamellae in the magnetite but none in the ilmenite.

\section{Sampling Procedure}

The samples were collected over two field seasons during the Australian winters of 1989 and 1990 . Sampling was designed to include one detailed traverse across the entire terrane $>50$ $\mathrm{km}$ ); supplemented by more dispersed sampling of the rest of the province to insure that all volumetrically significant units were adequately represented. The area has only been mapped at $1: 100,000$, thus much of the sampling was based on field observations and in situ magnetic susceptibility measurements, along with information from aerial photo interpretations (1:25,000 color and 1:80,000 black and white) and previous geophysical studies. Specimens were collected from approximately 200 sites while in situ susceptibilities were also measured at hundreds of other localities. Samples included oriented $2.5 \mathrm{~cm}$ drill cores (average three per site) and/or oriented hand samples. Laboratory measurements were made on core subsamples (two to four per core) or cores drilled from hand specimens.

\section{RESULTS}

\section{Low-Field Magnetic Susceptibility}

The magnetic susceptibility of rocks together with the Earth's magnetic field are the cause of induced magnetization.
Variation in induced magnetization contributes to the production of magnetic anomalies. Thus magnetic susceptibility measurements of crustal rocks play an important role in the understanding of the sources of long-wavelength magnetic anomalies. During this study, several thousand measurements of magnetic susceptibility were made, considering all laboratory and field measurements together. Field susceptibility measurements were made with either a Bartington MS2D coil, which is $18.5 \mathrm{~cm}$ in diameter and samples a hemispherical volume of approximately $6000 \mathrm{~cm}^{3}$, or a Bartington MS2F coil, which is $1.5 \mathrm{~cm}$ in diameter and samples a hemispherical volume of approximately $3 \mathrm{~cm}^{3}$. Laboratory measurements were made with an anisotropy of magnetic susceptibility bridge on $\sim 11 \mathrm{~cm}^{3}$ subcores. In situ measurements were compared to laboratory measurements to ensure that the core subsamples were representative of the field properties of the rock. There is a very good correspondence between these two sets of susceptibility measurements (Figure 3).

Susceptibility varies over three orders of magnitude, but some generalizations can be made when the rocks are grouped according to their field classification. Figure 4 shows that susceptibility has a strong dependence on both rock type and metamorphic grade, with granulites being by far the most highly susceptible rock type in general. Breaking down the 


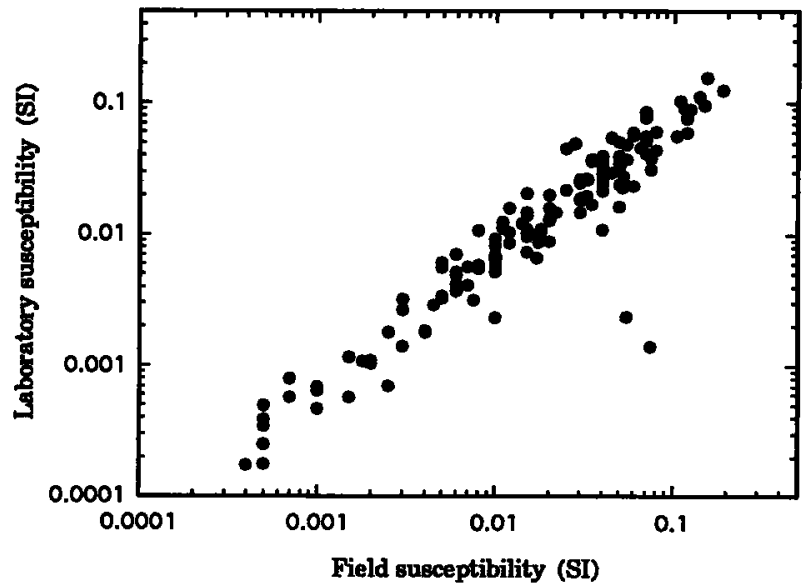

Fig. 3. Comparison of magnetic susceptibility per unit volume from subcores $\left(-11 \mathrm{~cm}^{3}\right)$ measured in the laboratory and susceptibility measurements made in the field $\left(-6000 \mathrm{~cm}^{3}\right.$ volume is sampled by field coil) at the sampling location. The approximate linear correlation suggests that laboratory measurements are representative of field properties. The slight offset from a one-to-one correlation is likely due to inegular shapes of the outcrops, a slight calibration offset for the field coil, and/or surficial weathering. The dispersion in the data is probably due to the heterogeneity of the outcrop.

granulites by composition does not reveal any major trend (Figure $4 b$ ). The granulites are the most magnetic rock type with a median magnetic susceptibility of 0.018 SI. This gives an induced magnetization of $0.7 \mathrm{~A} / \mathrm{m}$ in a magnetic field of $0.05 \mathrm{mT}(0.5 \mathrm{Oe})$, the approximate value of the Earth's field in Central Australia. We note that this value for induced magnetization, for the most magnetic rock type, is still a factor of two less than the magnetization contrasts of the Australian continental crust calculated by Mayhew and Johnson [1987] from the inversion of the Magsat data for Australia. Throughout this paper we have presented median values for susceptibility, natural remanent magnetization, and Koenigsberger ratios; mean values are between one third and a factor of two larger than the median values.

It has been suggested that the increase of susceptibility with temperature, known as the Hopkinson effect, may contribute significantly to long-wavelength anomalies [Dunlop, 1974], since the assumed sources reside at some depth in the earth and thus are at elevated temperature. The Hopkinson effect occurs when the temperature of a magnetic grain is between its blocking temperature $\left(T_{b}\right)$ and its Curie temperature $\left(T_{c}\right)$; therefore the magnetic grain is superparamagnetic and can be easily aligned in a weak magnetic field. Thus the magnitude of the Hopkinson effect is grain-size dependent and is most pronounced in single-domain (SD) material where $T_{b}$ is significantly below $T_{c} . T_{b}$ is generally within $100^{\circ} \mathrm{C}$ of $T_{c}$ for SD magnetite, therefore the Hopkinson peak occurs over a fairly restricted temperature range. In multidomain (MD) material the blocking temperature for complete demagnetization is near the Curie temperature and the magnetic susceptibility is approximately inversely proportional to the demagnetizing factor, which is nearly temperature independent. Thus MD grains should only exhibit a small Hopkinson peak near the minerals' $T_{c}$. The magnetic susceptibility for typical Arunta Block samples remains relatively constant with temperature until above $550^{\circ} \mathrm{C}$ where it drops sharply (Figure 5), suggesting first that relatively pure magnetite is the
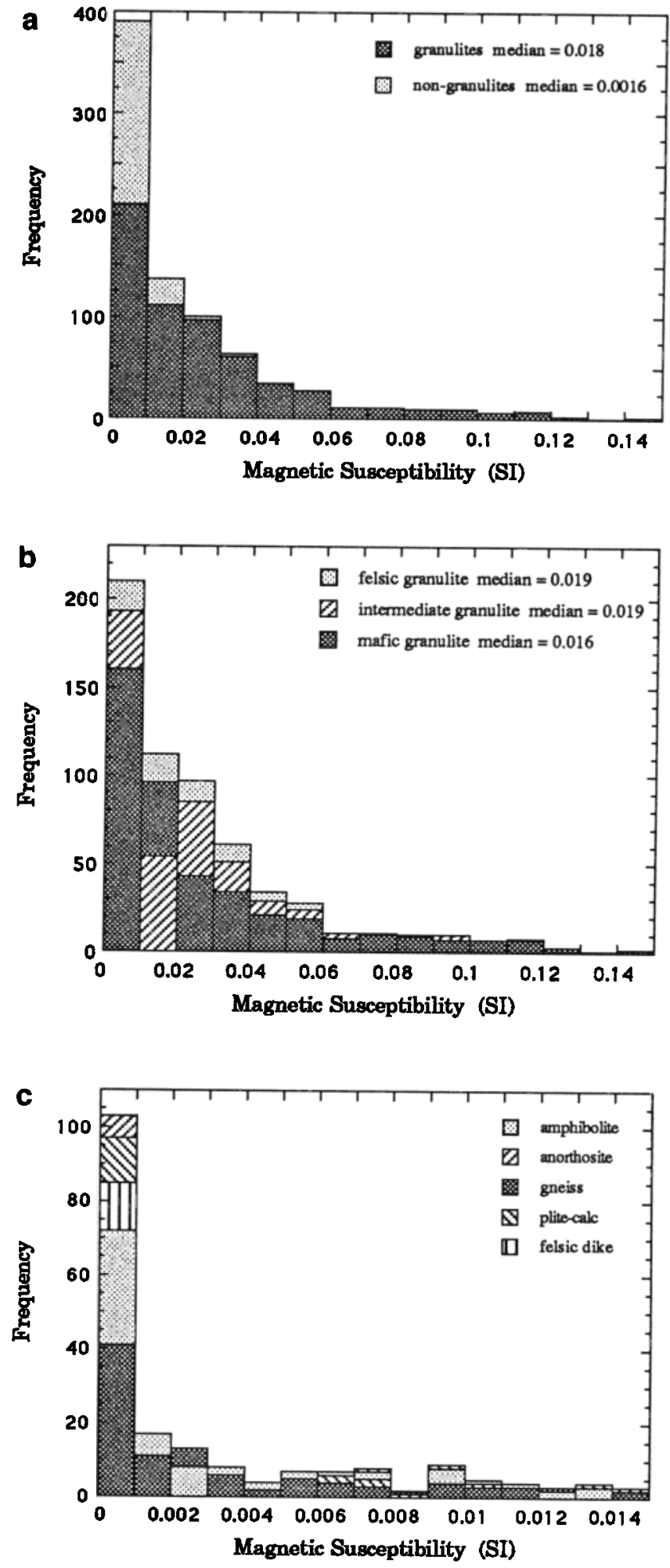

Fig. 4. A histogram of the magnetic susceptibility for (a) the Arunta Block samples (see text for definition of granulite and nongranulite); (b) the granulites, with subdivisions based on the percentage of ferromagnesian minerals (see text); (c) nongranulites separated by rock type (note order of magnitude difference in scale).

dominant contributor to the susceptibility. Second, the Hopkinson effect does not seem to be important, thus confirming observations made during other studies of crustal rocks [Schlinger, 1985; Williams et al., 1985; Shive and Fountain, 1988; Bina and Henry, 1990]. 


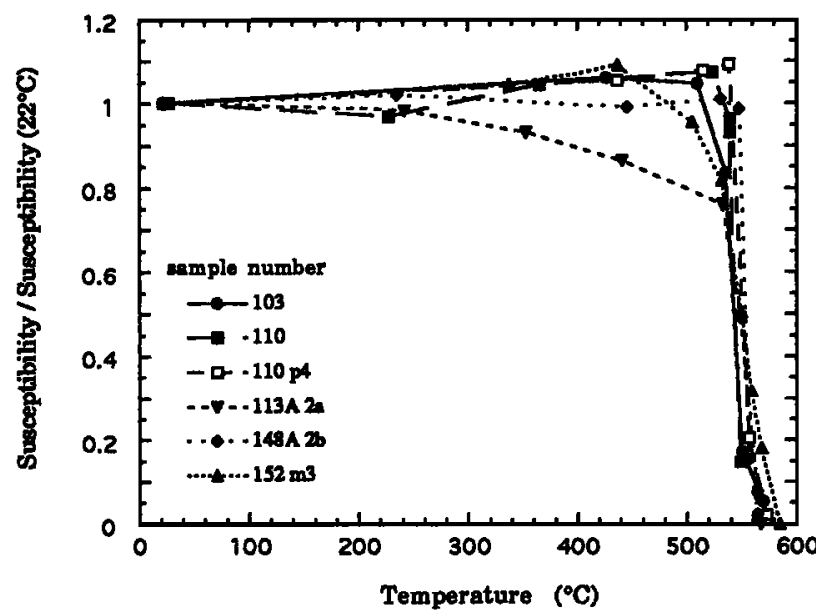

Fig. 5. Magnetic susceptibility versus temperature for representative granulite samples, with the susceptibility normalized to the room temperature value. Susceptibility is relatively constant with temperature to near the Curie temperature $\left(550-585^{\circ} \mathrm{C}\right)$ where it decreases rapidly; thus there is no significant Hopkinson effect for these samples.

Pressure increases with depth in the Earth and this also affects magnetic susceptibility. The most important effect of hydrostatic pressure is to increase the Curie temperature of the magnetic mineral, which for magnetite amounts to approximately $2^{\circ} \mathrm{C} / \mathrm{kbar}$ [Samara and Giardini, 1969; Schult, 1970]. Thus rocks residing in the lower crust, containing relatively pure magnetite as their magnetic carrier, will have a Curie temperature of approximately $600^{\circ} \mathrm{C}$, since pressures at these depths in the continental crust typically range from 10 to $20 \mathrm{kbar}$. Hydrostatic pressure, up to $2 \mathrm{kbar}$, does not affect the magnitude of magnetic susceptibility [Martin, 1980; Martin and Noel, 1988]. Uniaxial stress, however, can change the magnitude of magnetic susceptibility, the amount and sign of which depends on the orientation of the applied stress relative to the magnetic field. When the applied stress is parallel to the magnetic field the susceptibility decreases, whereas when the stress and field are perpendicular there is a somewhat smaller increase in magnetic susceptibility [Nagata, 1966, 1970]. The amount of change is reversible and dependent on both composition and magnetic grain size, but it can be $\pm 40 \%$ at 2 kbar of differential stress [Nagata, 1966, 1970; Martin 1980]. Uniaxial stresses greater than 1-2 kbar are unlikely to be sustained in materials residing at elevated temperatures in the lower crust [e.g., Fountain, 1989].

The anisotropy of magnetic susceptibility (AMS) was measured for all laboratory samples and averaged $28 \%$ with the most anisotropic samples having values of nearly $100 \%$, where percent anisotropy is calculated as [(AMS $\left.S_{\max }-\mathbf{A M S}_{\min }\right) /$ AMS $\left.S_{\text {mean }}\right] \times 100$. Since the samples had such a large anisotropy, it was necessary to measure the AMS to calculate accurately the mean susceptibility. Values from a one axis measurement would be very dependent on which axis was measured. If the AMS axes are consistently oriented over a terrane, then its orientation relative to Earth's magnetic field would significantly affect the induced magnetization of the terrane.

\section{Natural Remanent Magnetization}

One of the most remarkable properties of these Arunta Block samples is their large natural remanent magnetization (NRM),
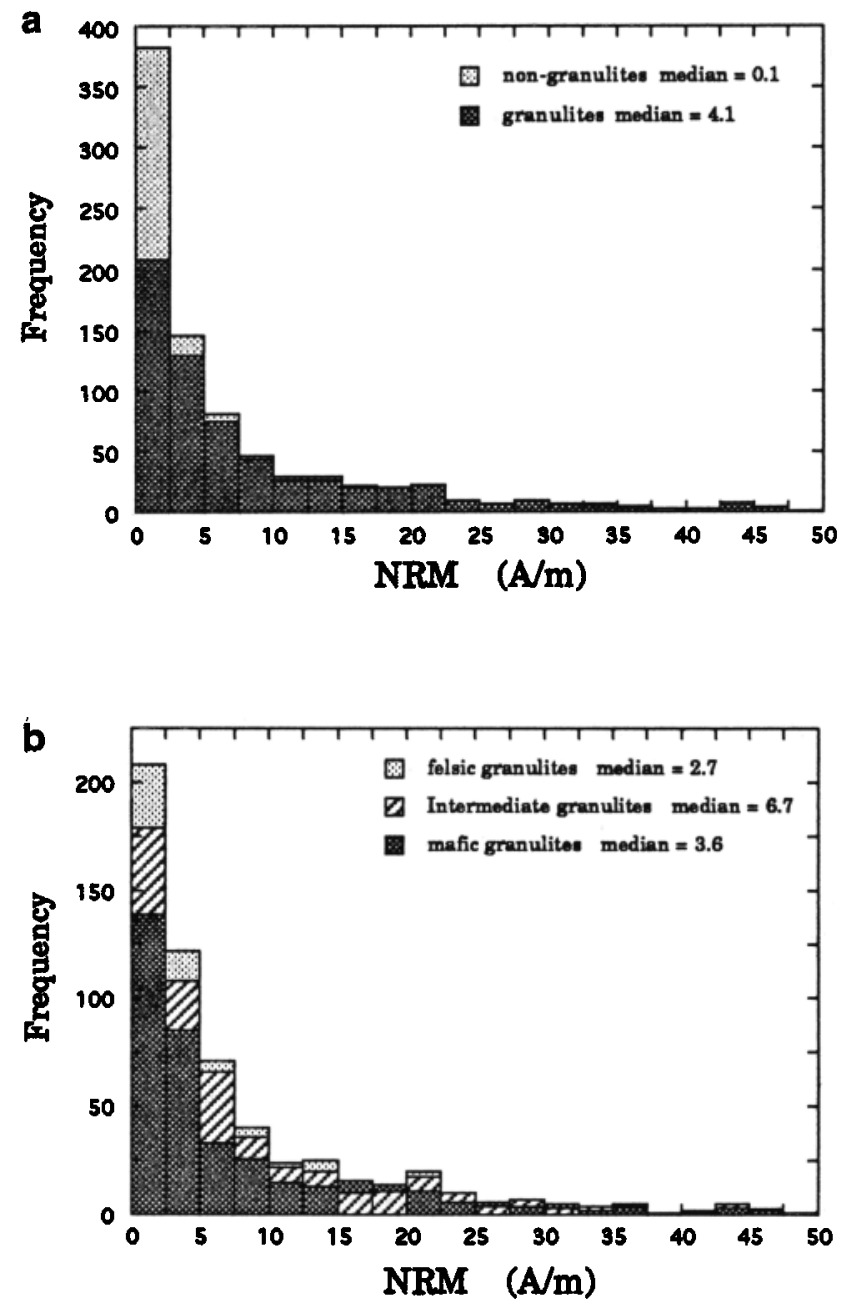

Fis. 6. Histograms of the namnl remanent magnetization for the Arunta Block samples (a) subdivided into granulite and nongranulite types as in Figure 4a, and (b) with the gramulites subdivided similar to Figure $4 b$.

which has also been observed in other rocks from the Arunta Block [Mutton and Show, 1979]. Figure 6, a histogram of the NRMs for this study, shows that the granulites have NRMs with a median of approximately $4.1 \mathrm{~A} / \mathrm{m}$. This magnetization is of the order that is necessary from models for the sources of long-wavelength anomalies. Characteristics similar to those recognized for susceptibility are observed for the NRM, e.g., the granulites have the highest magnetizations, but within the granulites there seems to be little dependence on the overall rock composition.

The stability of these NRMs as a function of time and temperature must be determined before the possible contribution of the NRM to magnetic anomalies can be assessed. Zero field storage for two weeks or more did not significantly affect the NRM intensity ( $<5 \%$ change) or its direction. Thermal demagnetization was carried out in air in a Schonstedt TSD-1 thermal demagnetizer with the $\sim 11 \mathrm{~cm}^{3}$ samples remaining at the peak temperature for $45 \mathrm{~min}$. The monitoring of susceptibility after each heating step suggests that very little alteration of the magnetic minerals occurred during thermal demagnetization. During thermal demagnetization the NRM was usually quite stable, with an average of $48 \%$ of the magnetization remaining after the $400^{\circ} \mathrm{C}$ 


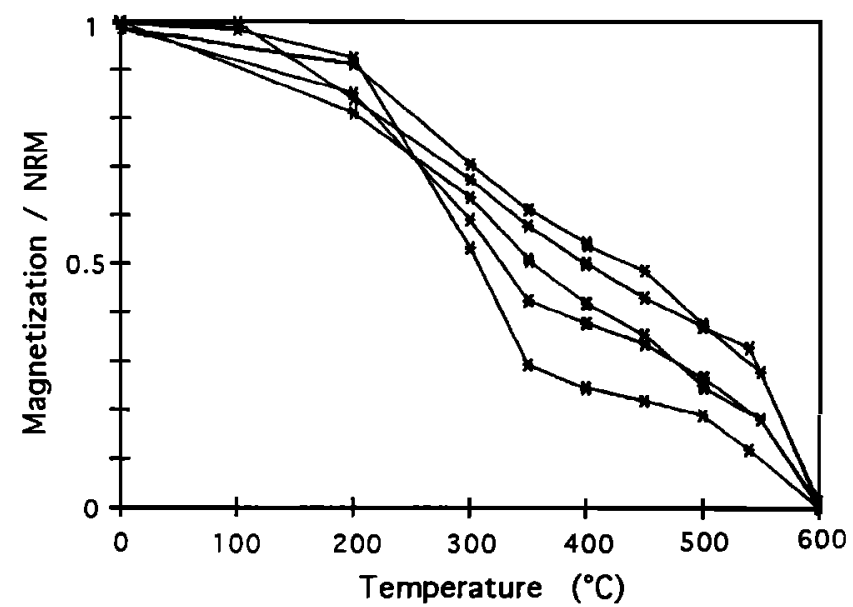

Fig.7. Thermal demagnetization of NRM's displaying the range of behavior observed for granulite samples. The magnetization is normalized to the initial NRM value. Note that the mean remanence remaining after $400^{\circ} \mathrm{C}$ for the 55 thermally demagnetized samples is $48 \%$.

demagnetization step for 55 samples (Figure 7). Since much of room temperature NRM remains at elevated temperature, NRM could contribute significantly to long-wavelength magnetic anomalies. Thermal demagnetization was usually completed between $550-600^{\circ} \mathrm{C}$, suggesting that magnetite is the dominant carrier of magnetic remanence. The NRM was also demagnetized using a Schonstedt GSD-1 altemating field (AF) demagnetizer. During AF demagnetization the samples typically lost half of their remanence by the $10 \mathrm{mT}$ (100 Oe) demagnetization level (Figure 8). The relative ease of AF demagnetization of MD material is due to the internal demagnetizing field within each grain [Stacey and Banerjee, 1974; Bailey and Dunlop, 1983].

The NRM must be along a consistent direction over a terrane if it is to be an important contributor to long-wavelength magnetic anomalies. The magnetization direction of exposed samples can be complicated by their uplift and tectonic history. Directional data from AF and thermal demagnetization revealed that the bulk of the samples NRMs were comprised of one or two directional magnetic components. The directional

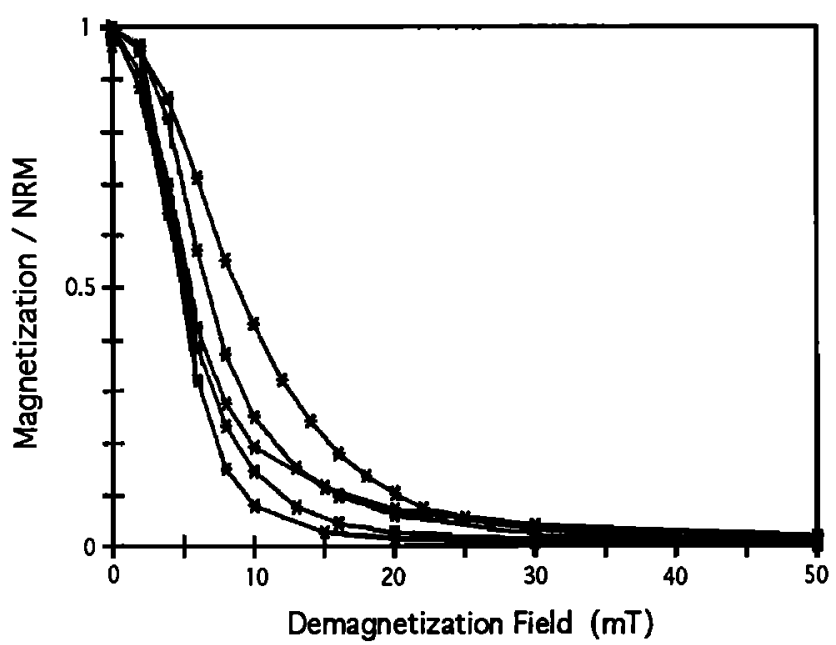

Fig. 8. Representative AF demagnetization character exhibited by the NRM's of Arunta block granulite samples. The magnetization is normalized to the initial NRM value. data are often consistent at individual sites (over tens of square meters) but not between sites (over kilometers). A probable cause for the variations in the original NRM direction is that during the progressive stages of uplift, different sites were magnetized at different times depending on their blocking temperature distributions and the lengths of time that they resided at various temperatures. In addition, some samples may have been affected by lightning. But rocks presently residing at elevated temperature within the crust would acquire a thermoviscous remanent magnetization along the present day geomagnetic field, and this would be in a nearly uniform direction over an entire terrane. Since all of the samples are oriented, using the directional data and the thermal unblocking data one may be able to constrain the uplift history of this block, but such a large scale, detailed demagnetization study has not been undertaken to date.

The effects of pressure on remanence, including demagnetization, piezo-remanent magnetization, and aftereffects, have been addressed in a variety of studies, mostly concentrating on the effect of deviatoric stress [e.g. Nagata and Carleton, 1969; Martin, 1980], not absolute pressure [Martin, 1988], which is the dominant component of stress in the lower crust. Applying a hydrostatic pressure of 2 kbar can cause the thermoremanent magnetization (TRM) to decrease by approximately $30 \%$, compared to the room pressure value [Martin, 1988]. During release of the pressure in zero field, the remanence remains relatively constant, i.e., it does not rebound to the previous value at room pressure. Piezoremanent magnetism (PRM) is the magnetization a sample acquires during the release of pressure while in a magnetic field [Nagata, 1970]. Since PRM is acquired during the release of pressure, rocks presently residing in the lower crust will not carry a significant PRM. The uplift of lower crustal samples to the surface generally takes tens of millions of years during which the Earth's field will reverse many times. Thus the resultant PRM is likely to be small. Therefore, if the remanence of a rock was acquired while it was at elevated pressure, the NRM that we measure in the lab will not be significantly affected by its subsequent pressure history. Studies have found that the rate of acquisition of viscous magnetization in titanomagnetite (TM60) greatly increases (210 times) at a uniaxial pressure of $<0.5 \mathrm{kbar}$ [Pozzi, 1975; Sporer, 1984], but no work has been done on the effect hydrostatic pressure may have on the acquisition of viscous magnetization in magnetite. All of the above work on pressure effects has been performed at room temperature; thus its direct application to the lower crust is unknown. It is likely that the sign of the changes will remain the same, but the amount may be quite different.

The AF demagnetization of NRM and thermal remanent magnetization (TRM in $0.1 \mathrm{mT}$ ) of several samples were compared to the AF demagnetization of their room temperature saturation isothermal remanent magnetization (IRM) by the method of Cisowski et al. [1990]. The NRMs are much easier to demagnetize than the TRMs (Figure 9), which suggests [Cisowski et al., 1990] that the NRMs of the samples are not a simple TRM, but contain significant secondary components. Rocks from high grade metamorphic terranes commonly carry a thermoviscous secondary remanence due to their remaining at elevated temperature for extended periods of time, which can then be locked in during the slow cooling of the terrane. The samples may also carry a chemical remanent magnetization or a viscous magnetization acquired in the present-day field, 


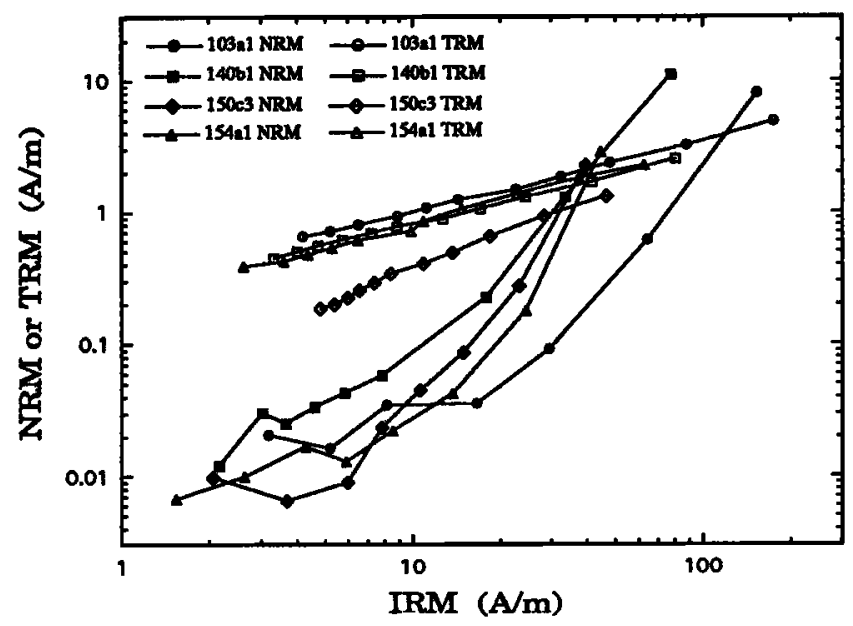

Fig. 9. The AF demagnetization of the NRM (solid symbols) and TRM (open symbols) for a few samples plotted versus the AF demagnetization of the sample's IRM on a log-log scale. According to Cisowski et al. [1990] the large difference in character between the (softer) NRM and (harder) TRM demagnetizations suggests that the NRM is not a simple TRM, but may contain secondary components such as viscous or chemical remanence.

although this is not observed in the stepwise demagnetization of most of the samples from this study.

Low temperature demagnetization was carried out on a number of samples by cooling them in liquid nitrogen to $77 \mathrm{~K}$ and then warming them to room temperature, all in zero field. This technique is most efficient at demagnetizing that portion of remanence that resides in coarse MD grains of magnetite [Dunlop and Argyle, 1991; Heider et al., 1992]. An average of $55 \%$ of the initial NRM remained after low temperature demagnetization of 20 samples (Figure 10). This suggests that much of the remanence resides in SD grains or small pseudosingle domain grains or, more likely, in relatively stable regions within MD grains which are not affected by lowtemperature, treatment in zero field but are easily demagnetized by an alternating field. There does not seem to be any correlation between the amount of demagnetization and the magnitude of the initial remanence.

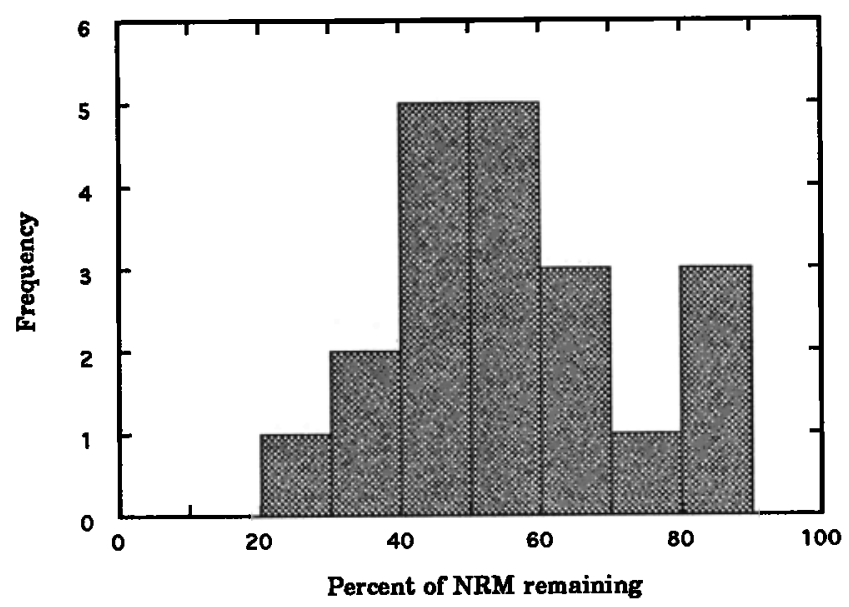

Fig 10. A histogram of the percentage of remanence remaining after low temperature demagnetization, i.e., cooling the samples to $77 \mathrm{~K}$ and rewarming to room temperature, all the while in zero field (mean $=55 \%$ ).

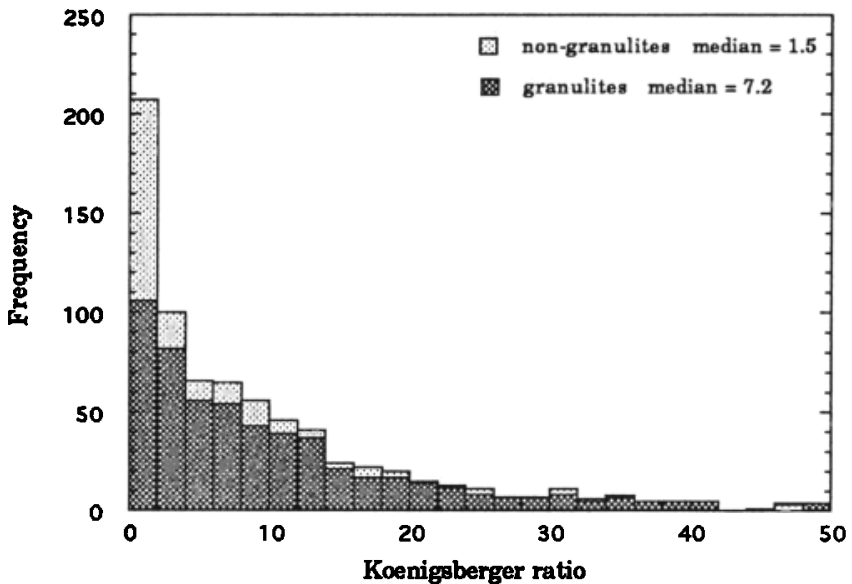

Fig. 11. A histogram of the Koenigsberger ratios for the Arunta Block samples which are subdivided into granulites and nongranulites as in Figure 4a. The median value for the granulites is 7.2 , suggesting that remanence is likely an important contributor to the observed magnetic anomalies.

\section{Koenigsberger Ratio}

The Koenigsberger ratio $(Q)$ is calculated by dividing the NRM by the induced magnetization. Thus the larger the Koenigsberger ratio, the more important is NRM for modeling purposes, with $Q=1$ indicating that the NRM and induced magnetization are equal. The Koenigsberger ratios for the samples of this study (Figure 11) were nearly always greater than one and for the granulites the median value is approximately seven. Samples with $Q$ values greater than 50 were excluded from all analysis, including NRM and susceptibility histograms, because of the high likelihood that they may have experienced a lightning strike. Within the granulites there again does not seem to be a strong dependence on composition, although $Q$ values for the more silicic rocks are generally the smallest. These large Koenigsberger ratios suggest that remanence could be a very important, if not the major component of magnetic anomalies. Since susceptibility is nearly independent of temperature and the NRMs are relatively resistant to thermal demagnetization, the Koenigsberger ratios will be greater than one even at the elevated temperatures where the source rocks of longwavelength anomalies reside.

\section{Rock Magnetism}

Saturation magnetization $\left(J_{s}\right)$ was measured as a function of temperature $(T)$ from $22^{\circ} \mathrm{C}$ to above $600^{\circ} \mathrm{C}$ on $\sim 100 \mathrm{mg}$ subsamples using a Princeton Applied Research Vibrating Sample Magnetometer (VSM). The measurements were carried out in helium after evacuating the sample chamber several times and back filling it with helium to facilitate thermal equilibration while reducing the chance of oxidation of the sample. The $J_{s}$ versus $T$ curves were reversible with little evidence for changes in the samples after heating. The Curie temperatures calculated from these $J_{s}$ versus $T$ curves are nearly always between $550-585^{\circ} \mathrm{C}$ (Figure 12), which is typical of a titanium-poor magnetite. This is consistent both with what has been observed in other crustal cross sections [Schlinger, 1985; Williams et al., 1985; Shive and Fountain, 1988; Wasilewski and Warner, 1988] and with the petrologic 
a
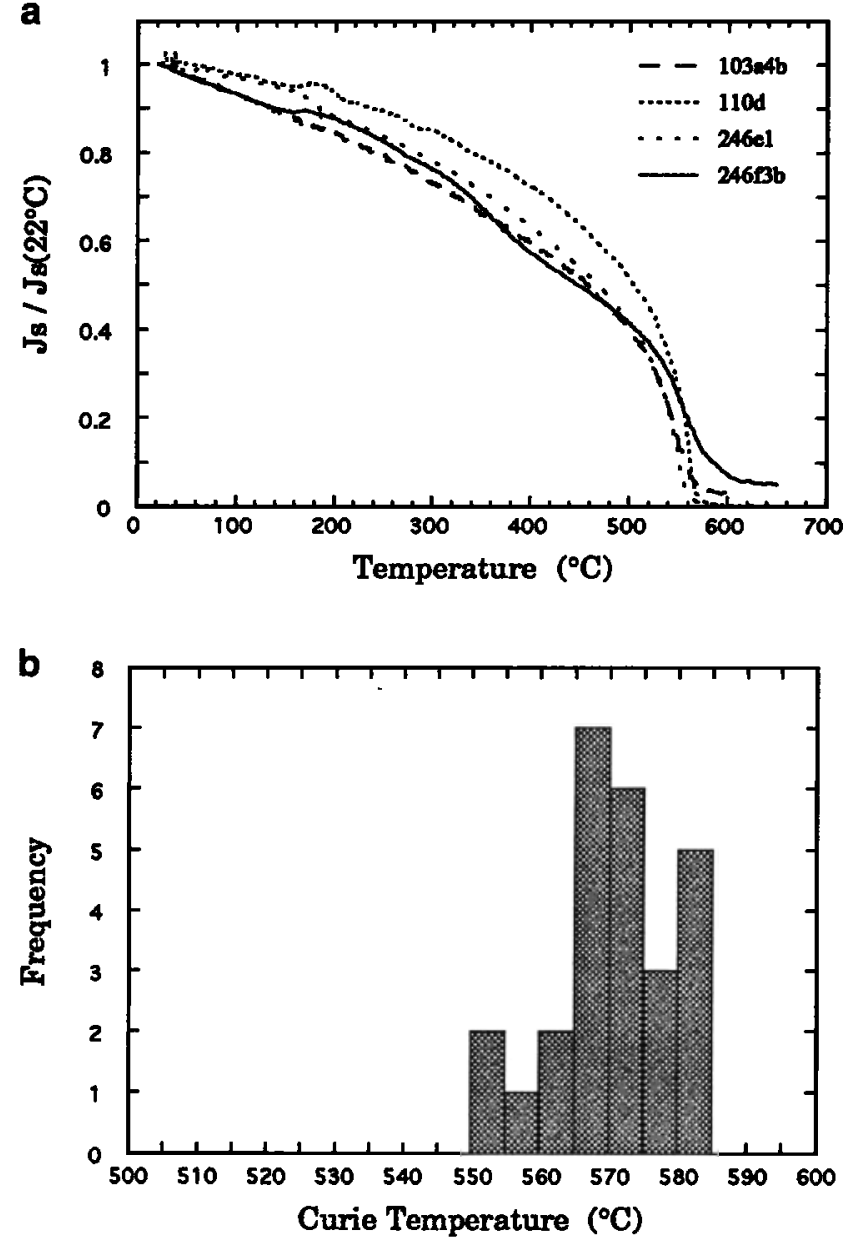

Fig. 12. (a) A representative saturation magnetization versus temperature curve from a sample chip $(-100 \mathrm{mg})$ from which the Curie temperatures were determined. (b) A histogram of the Curie temperatures, which suggest that the dominant magnetic mineral is relatively pure magnetite $\left(\right.$ mean $\left.=567^{\circ} \mathrm{C}\right)$; note abscissa temperature range is from 500 to $600^{\circ} \mathrm{C}$.

arguments of Frost [1991]. There were a few instances where two Curie temperatures existed (e.g., Figure 12, sample 246f3b). The dominant one was between $560-585^{\circ} \mathrm{C}$, suggesting magnetite, and the other between $300-400^{\circ} \mathrm{C}$, which could be due to titanomagnetite, but more probably is due to pyrrhotite [Dekkers, 1989], as iron sulfide minerals are common trace accessories.

Hysteresis loops were measured on the same $\sim 100 \mathrm{mg}$ subsamples used for $J_{s}$ versus $T$ curves and/or on $11 \mathrm{~cm}^{3}$ cores using the VSM. Figure 13 displays the ratios of the hysteresis parameters plotted on a Day et al. [1977] type diagram, where $J_{r s}$ is the saturation remanent magnetization, $H_{c r}$ the remanent coercive force, and $H_{c}$ the coercivity. Such a representation provides qualitative information on the magnetic grain size: fine grains plot in the upper left and larger grains in the lower right. The data indicate a range of magnetic grain sizes from pseudo-single domain (PSD) to large multidomain. The hysteresis loops suggest an average grain size $(<10 \mathrm{~mm})$ for the magnetite, which is smaller than what is observed optically (Figure 2). A possible explanation for this is that when one observes thin sections optically, the eye is drawn to the larger grains, even though there may be many smaller grains, including grain sizes near or below optical resolution. Since

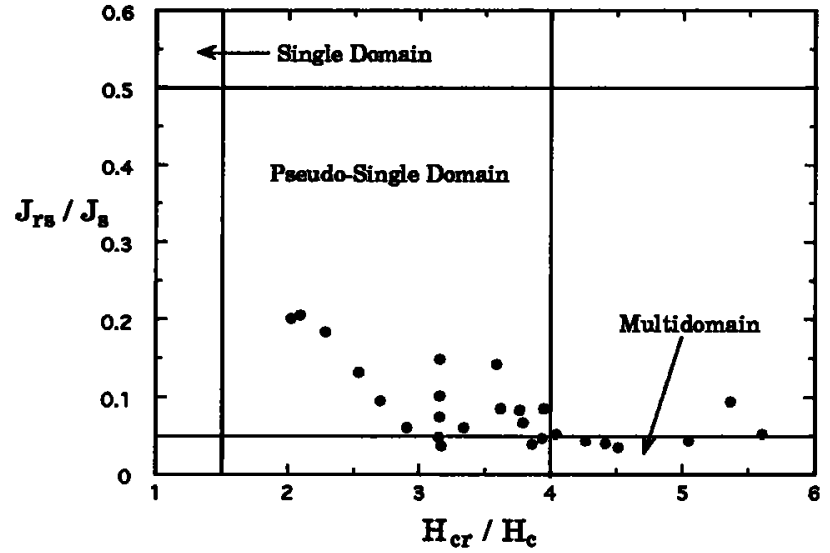

Fig. 13. The hysteresis ratios plotted on a Day et al. [1977] - type diagram suggest that the bulk magnetic grain size is in the pseudo-singledomain to multidomain region. $J_{s}$ is saturation magnetization, $J_{r s}$ is saturation remanent magnetization, $H_{C}$ is coercivity, and $H_{c r}$ is remanent coercive force.

hysteresis loops measure the bulk properties, these smaller grains may significantly affect the overall character of the loop and the individual parameters. Another potentially important contributor to the apparent discrepancy in grain size is the magnetite microstructures (Figures $2 c$ and $2 d$ ) of some samples. It has been noted, for example by Hartstra [1982] and Parry [1981], that microstructures can significantly affect magnetic properties, especially the hysteresis loops. Thus these fine intergrowths may cause the coarse magnetites to behave as much smaller grains.

Elevated-temperature hysteresis loops were measured on a few selected samples to increase our understanding of how the magnetic properties may vary with depth in the Earth. As might be expected, the loop parameters all decrease with increasing temperature, but what is more interesting is how their ratios change (Figure 14). The ratios show that there is generally only a small change in the effective magnetic grain size below $500^{\circ} \mathrm{C}$, but above this temperature the magnetic grain size increases dramatically. This is probably due to a change in the equilibrium number of domains [Heider, 1990]

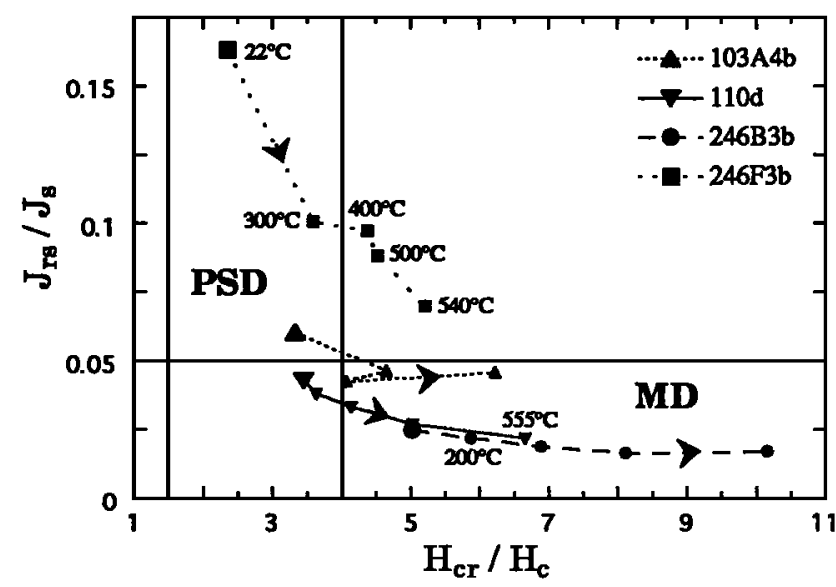

Fig. 14. Elevated temperature hysteresis parameters are plotted on an expanded portion of a Day et al. diagram. The larger symbol is the room temperature measurement, and moving along the line between points (see arrowheads) the temperature increases to approximately 400,500 , and $540^{\circ} \mathrm{C}$. Individual temperature steps are labeled for sample $246 \mathrm{f} 3 \mathrm{~b}$ as are supplementary temperature measurements for other samples. 
a

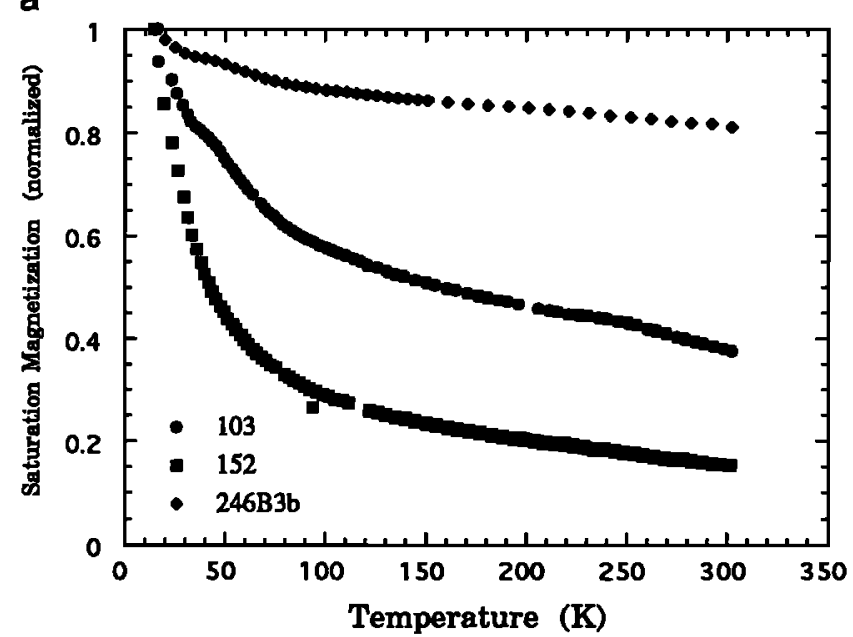

b

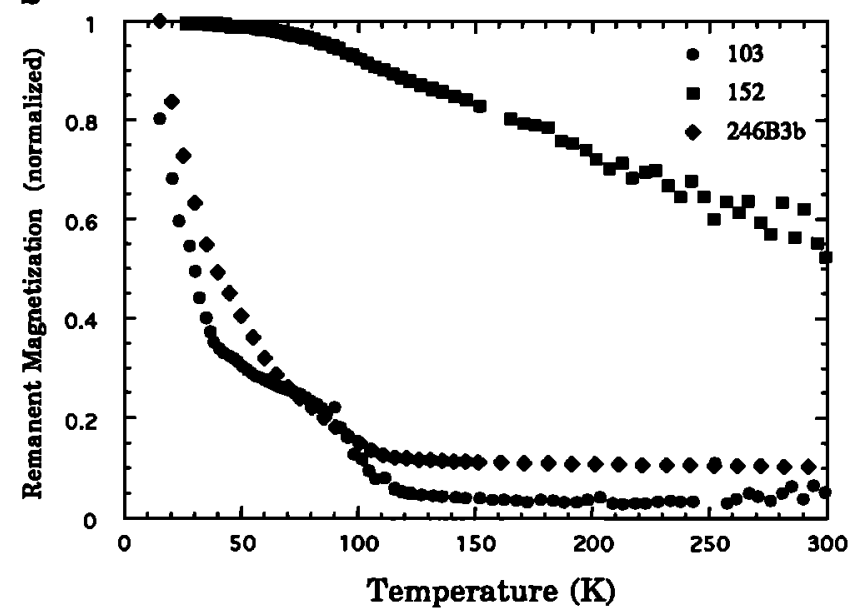

Fig. 15. (a) The saturation magnetization in a $0.3 \mathrm{~T}$ field (nomalized to the $15 \mathrm{~K}$ value) versus temperature from 15 to $300 \mathrm{~K}$ for a few chips $(\approx 100 \mathrm{mg}$ ). The decrease in magnetization between 15 and $100 \mathrm{~K}$ is due to the magnetic ordering of ilmenite and to the paramagnetic minerals, while the behavior above $100 \mathrm{~K}$ is dominated by thermal decay of the magnetite magnetization. (b) Saturation remanence normalized to $15 \mathrm{~K}$ $\left(\mathrm{SIRM}_{15}\right)$ and heated in zero field to $300 \mathrm{~K}\left(27^{\circ} \mathrm{C}\right)$ with a measurement of the remanence made every $5-10^{\circ}$ on chips $(* 100 \mathrm{mg}$ ) from a few samples. The change in slope near $100 \mathrm{~K}$ is due to the Verwey transition in magnetite while the contribution to remanence that is demagnetized a $<80 \mathrm{~K}$ is likely from iron poor ilmenite or pynhotite $(35 \mathrm{~K})$ components.

and/or the type and strength of domain wall pinning mechanisms as temperature increases. Thus at elevated temperatures, even though there is no actual change in the grain size of the magnetic minerals, the rocks behave like coarser multidomain specimens, i.e., they are magnetically softer. This suggest that the remanence may be less stable at elevated temperatures, allowing easier remagnetization of this portion of crust, and possibly resulting in the acquisition of an elevated temperature viscous magnetization.

Low temperature measurements were made on a few samples to help characterize the magnetic minerals and understand their rock magnetic properties. These measurements were made from $15 \mathrm{~K}$ to room temperature on $100-300 \mathrm{mg}$ subsamples in a Quantum Design MPMS2. The experiments included (1) extending $J_{s}$ versus $T$ curves from $295 \mathrm{~K}\left(22^{\circ} \mathrm{C}\right)$ down to $15 \mathrm{~K}$, (2) measuring the saturation isothermal remanence at $15 \mathrm{~K}$ $\left(\operatorname{SIRM}_{15}\right)$ and then heating it to $300 \mathrm{~K}$ in zero field, while measuring the remanence value every $5-10 \mathrm{~K}$, (3) hysteresis loop measurements at $15,100,150$ and $300 \mathrm{~K}$. $J_{s}$ versus $T$ curves measured during heating from $15 \mathrm{~K}$ are characteristic of magnetite with a paramagnetic component that sometimes dominates at low temperature (Figure 15a). The SIRM 15 , when heated in zero field, displays a variety of features (Figure $15 b$ ). These include an unblocking temperature in the vicinity of 50 $\mathrm{K}$, most likely due to iron-poor ferroilmenite [Ishikawa and Akimoto, 1957; Banerjee, 1991] or pyrrhotite [Rochette et al., 1990]; a decrease in remanence in the $100-120 \mathrm{~K}$ range, most likely due to the magnetocrystalline anisotropy constant, $k_{1}$, of magnetite going to zero in this temperature interval; and a general decrease in remanence due to both thermal demagnetization and the decrease in $J_{s}$ with temperature. The component that dominates at a given temperature depends on the proportions of the different minerals. From the above measurements, and from low temperature hysteresis loops, there is no evidence for a large fraction of magnetite to be superparamagnetic (SP) or near-SP at room temperature. However, this conclusion is somewhat complicated by the presence of the iron poor ferroilmenite and pyrrhotite. SP material is not important for the interpretation of remanent magnetization in the lower crust, but it may affect magnetic susceptibility and the measured hysteresis parameters.

\section{DISCUSSION AND CONCLUSIONS}

The dominant magnetic mineral in these Arunta Block samples is magnetite with an average Curie temperature of $567^{\circ} \mathrm{C}$, which is consistent with other crustal studies. Magnetite is petrologically the stable magnetic phase under most prograde granulite facies conditions [Frost, 1991]. The most prominent variations of magnetization within the section are generally metamorphically controlled, an observation similar to that made by Schlinger [1985] and Wasilewski and Warner [1988]. The most magnetic rocks are the granulites, but within the granulites the magnetization is independent of the percentage of bulk ferromagnesian minerals. The bulk-rock composition is only of secondary importance, contrary to the observations of Schlinger [1985] and Wasilewski and Warner [1988], who found the most magnetic units to be dominated by mafic compositions.

The remanent magnetizations of the granulite samples have a median value of $4.1 \mathrm{~A} / \mathrm{m}$, which is large enough to produce most of the observed long-wavelength magnetic anomalies. Even at a temperature of $400^{\circ} \mathrm{C}$, nearly half of the remanence of the Arunta Block samples remains. Thus, even though the source of the anomalies are rocks that presently reside at elevated temperature, remanence can contribute significantly to the anomalies. Large NRMs appear to be characteristic of the Arunta Block as they were also reported by Mutton and Shaw [1979] in the only other magnetic study of Arunta block granulites. These results are in contrast to studies of the Superior craton by Williams et al. [1985] and Shive and Fountain [1988], who report that the terranes are relatively non-magnetic irrespective of rock composition or metamorphic grade. The overriding reason for the difference in magnetic properties between these studies is the amount of magnetite in the samples. The difference in the magnetite content of the Arunta Block and the Canadian Shield is undoubtedly related to the petrogenetic differences between the terranes. The terranes studied by Williams et al. [1985] and Shive and Fountain [1988] are both of Archean age, whereas the Arunta Block formed in the early Proterozoic. The 
Canadian Shield and Arunta Block studies contain a wide range of rock types, but the dominant lithology of the Canadian studies are granitic to tonalitic gneisses, whereas the Arunta Block is dominated by intermediate to mafic granulites. The processes that form these lithologies are different: the Superior Terranes likely formed in a magmatic arc environment beneath greenstone belts [Percival, 1989], while the Arunta Block likely formed due to mantle upwelling and underplating of the lower continental crust [Etheridge et al., 1987]. Even though these terranes were metamorphosed under similar pressuretemperature conditions, i.e., granulite facies, the phase equilibria and thus oxygen fugacity buffers are different [Percival, 1983; Glikson, 1987a]. The amount of magnetite that forms is related not only to the rock composition but also the ferrous/ferric iron ration, the oxygen fugacity, and a variety of other factors that are poorly understood [Frost, 1991].

Hydrostatic pressure increases the Curie temperature of rocks presently at depth in the Earth by a few degrees $\left(\approx 2^{\circ} \mathrm{C} / \mathrm{kbar}\right)$, whereas its effect on the acquisition of viscous magnetization has not been studied. In a field of $0.05 \mathrm{mT}$, the magnetic susceptibility of the samples produces an induced magnetization of $<1 \mathrm{~A} / \mathrm{m}$. The susceptibility remains relatively constant with temperature up to near the Curie temperature where it decreases to zero. There is no significant Hopkinson peak at elevated temperature, which is consistent with other studies of lower crustal rocks and with predictions for multidomain magnetite from theoretical arguments. The granulites have a median Koenigsberger ratio of 7.2. Thus magnetic remanence must be considered in any analysis of long-wavelength magnetic anomalies, in contrast to simple theoretical arguments by Shive [1989], who suggests that remanence cannot be greater than the magnetic susceptibility by more than $25 \%$ [Worm, 1989].

Preliminary elevated temperature viscous remanent magnetization experiments by Kelso and Banerjee [1991] suggest that the granulites have viscosity coefficients at $400^{\circ} \mathrm{C}$ which, when extrapolated over the Brunhes epoch, give a magnetization of approximately $4 \mathrm{~A} / \mathrm{m}$. Considering the slow cooling rates for regionally uplifted terranes relative to the magnetic field reversal frequency and the large blocking temperature distribution of crustal rocks, it is unlikely that a large thermoviscous remanence would be locked in unless the terrane happens to cool during a long polarity interval, i.e., a superchron. The origin of the remanence in these Australian samples is difficult to determine from the present study, but for rocks presently residing in the lower crust it could be predominantly a thermoviscous magnetization acquired along the present day field, i.e., parallel to the induced magnetization. If this is the case, then the magnetic anomalies can be modeled as if they are due solely to the magnetic susceptibility, but it must be kept in mind that this is not the actual magnetic susceptibility but an "effective susceptibility" due to the magnetic susceptibility and the thermoviscous remanent magnetization. The latter may be the dominant component. Rocks with magnetic properties similar to these Arunta Block samples are capable of producing the longwavelength magnetic anomalies observed by the Magsat satellite and other surveys if they are juxtaposed with rocks that are relatively nonmagnetic, for example, rocks with properties similar to those from crustal studies in the Canadian shield such as the Kapuskasing zone of Ontario [Shive and Fountain, 1988] or the Pikwitonei-Cross Lake subprovinces of Manitoba [Williams et al., 1985].
Acknowledgments. We thank Peter Wasilewski, P.K.'s mentor at NASA, who provided direction and insights throughout this project and generously made available his laboratory where the elevated temperature susceptibility measurements were made. We would also like to thank Russell Shaw at the Australian Geological Survey Organization who has been the source of many valuable discussions conceming the geology and tectonic development of Central Australia. Shaw provided us with data from his unpublished Ph.D. dissertation, many of the maps and aerial photos used during mapping, along with technical field assistance. This project was supported primarily through NASA grant NGT-50421. The Northem Territory Geological Survey provided field support and made their facilities in Alice Springs available to us. Field support was also provided by the Geological Society of America, Sigma Xi, and the University of Minnesota, Department of Geology and Geophysics. C.T. acknowledges support from a McKnightLand Grant professorship. We wish to thank the Institute for Rock Magnetism (RM) in Minneapolis for the use of its facilities. The IRM is funded by the Keck Foundation, the National Science Foundation, and the University of Minnesota. IRM contribution 9210.

\section{REFERENCES}

Arkani-Hamed, J., Thermoremanent magnetization of the oceanic lithosphere inferred from a thermal evolution model: implications for the source of marine magnetic anomalies, Tectonophysics, 192, 81-96, 1991.

Bailey, M. E., and D. J. Dunlop, Altemating field characteristics of pseudo-single domain $(2-14 \mu \mathrm{m})$ and multidomain magnetite, Earth Planet. Sci. Lett., 63, 335-352, 1983.

Banerjee, S. K., Magnetic properties of Fe-Ti Oxides, in Oxide Minerals: Petrologic and Magnetic Significance, vol. 25, edited by D. H. Lindsley, pp. 107-128, Mineralogical Society of America, Chelsea, Mich., 1991.

Berg, J. H., R. J. Moscati, and D. L. Herz, A petrologic geotherm from a continental rift in Antaretica, Earth Planet. Sci. Lett., 93, 98-108, 1989.

Bina, M. M., and B. Henry, Magnetic properties, opaque mineralogy and magnetic anisotropies of serpentinized peridotites from ODP Hole 670A near Mid-Atlantic Ridge, Phys. Earth Plonet. Inter., 65, 88-103, 1990.

Black, L. P., and R. D. Shaw, U-Pb zircon chronology of prograde Proterozoic events in the Central and Southem Provinces of the Arunta Block, Central Australia, Aust.J. Earth Sci., 39, 153-171, 1992.

Black, L. P., R. D. Shaw, and L. A. Offe, The age of the Stuart Dyke Swarm and its bearing on the onset of Late Precambrian sedimentations in Central Australia., J. Geol. Soc. Aust., 27, 151-155, 1980.

Black, L. P., R. D. Shaw, and A. J. Stewart, Rb-Sr geochronology of Proterozoic events in the Arunta Inlier, Central Australia, BMR $J$. Aust. Geol. Geophys., 8, 129-138, 1983.

Brown, L., D. Wille, and L. Zheng, COCORP: new perspectives on the deep crust, Geophys. J. R. Astron. Soc., 89, 47-54, 1987.

Cisowski, S., J. Dunn, M. Fuller, and P. J. Wasilewski, NRM:IRM(s) demagnetization plots of intrusive rocks and the origin of the their NRM, Tectonophysics, 184, 35-54, 1990.

Collins, W. J., and C. Teyssier, Crustal scale ductile fault systems in the A runta Inlier, Central Australia, Tectonophysics., 158, 49-66, 1989.

Day, R., M. Fuller, and V. A. Schmidt, Hysteresis properties of titanomagnetites: grain-size and compositional dependence, $P$ hys. Earth Planet. Inter., 13, 260-266, 1977.

Dekkers, M. J., Magnetic properties of natural pyrrhotite II High- and low-temperature behavior of $J_{\mathrm{n}}$ and TRM as a function of grain size, Phys. Earth Planet. Inter., 57, 266-283, 1989.

Dunlop, D. J., Thermal enhancement of magnetic susceptibility, $J$. Geophys., 40, 4339-4351, 1974.

Dunlop, D. J., and K. S. Argyle, Separating multidomain and singledomain-like remanences in pseudo-single domain magnetites (215-540 $\mathrm{nm}$ ) by low-temperature demagnetization, J. Geophys. Res., 96, 20072017, 1991.

Etheridge, M. A., R. W. R. Rutland, and L. A. I. Wyborn, Orogenesis and tectonic process in the early to middle Proterozoic of Northem Australia, in Proterozoic Lithospheric Evolution, Geodyn. Ser., vol. 17, edited by A. Kröner, pp. 131-147, AGU, Washington, D.C., 1987.

Fountain, D. M., Growth and modification of lower continental crust in extended terrains: the role of extension and magmatic underplating, in Properties and Processes of Earth's Lower Crust, Geophys. Monogr. Ser., vol. 51, edited by R. F. Mereu, S. Mueller, and D. M. Fountain, pp. 287-289, AGU, Washington, D.C., 1989. 
Frost, B. R., Magnetic petrology: factors that control the occurrence of magnetite in crustal rocks, in Oxide Minerals: Petrologic and Magnetic Significance, vol. 25, edited by D. H. Lindsley, Pp. 489-506, Mineralogical Society of America, Chelsea, Mich., 1991.

Frost, B. R., and P. N. Shive, Magnetic mineralogy of the lower continental crust, J. Geophys. Res., 91, 6513-6521, 1986.

Glikson, A. Y., An upthrusted Early Proterozoic basic granuliteanorthosite suite and anatectic gneisses, south-west Arunla Block, Central Australia: Evidence on the nature of the lower crust, Trans. Geol. Soc. So. Afr., 89, 263-283, $1987 a$.

Glikson, A. Y., Regional structure and evolution of the Redbank-Mount Zeil thrust zone: a major lineament in the Arunta Inlier, Central Australia, BMR J. Aust. Geol. Geophys., 10, 89-107, $1987 b$.

Goleby, B. R., C. Wright, C. D. N. Collins, and B. L. N. Kennet, Seismic reflection and refraction profiling across the Arunta Block and Nagalia and Amadeus Basins, Aust. J. Earth Sci., 35, 275-294, 1988.

Hahn, A. G., and H. A. Roeser, The magnetization of the lower continental crust in Properties and Processes of Earth's Lower Crust, Geophys. Monogr., vol. 51, IUGG, vol. 6, edited by R. F. Mereu, S Mueller, and D. M. Fountain, pp. 247-253, International Union of Geodesy and Geophysics and AGU, Washington, D.C., 1989.

Hartstra, R. L., Grain-size dependence of initial susceptibility and saturation magnetization-related parameters of four natural magnetites in the PSD-MD range, Geophys. J. R. Astron. Soc., 71 , $477-495,1982$

Heider, F., Temperature dependence of domain structure in natural magnetite and its significance for multidomain TRM models, Phys. Earth Planet. Inter., 65, 54-61, 1990.

Heider, F., D. J. Dunlop, and H. C. Soffel, Low-temperature and alternating field demagnetization of saturation remanence and thermoremanence in magnetite grains $(0.37 \mu \mathrm{m}$ to $5 \mathrm{~mm}), J$. Geophys. Res., 97, 9371-9381, 1992.

Ishikawa, Y., and S. Akimoto, Magnetic properties of the $\mathrm{FeTiO}_{3}-\mathrm{Fe}_{2} \mathrm{O}_{3}$ solid solution series, J. Phys. Soc. Jpn., 12, 1083-1098, 1957.

Kelso, P. R., and S. K. Banerjee, An experimental study of the temperature dependence of viscous remanent magnetization of coarse grained natural and synthetic magnetite, Eos Trans. AGU, 72 (44) suppl., 137, 1991.

Lambeck, K., G. Burgess, and R. D. Shaw, Teleseismic travel-time anomalies and deep crustal structure in Central Australia, Geophys. J. 94, 105-124, 1988.

Martin, R. J., III, Is piezomagnetism influenced by microcracks during cyclic loading?, J. Geomegn. Geoelectr., 32, 741-755, 1980.

Martin, R. J., III, and J. S. Noel, The influence of stress path on thermoremanent magnetization, Geophys. Res. Lett., 15, 507-510, 1988.

Mayhew, M. A., and B. D. Johnson, An equivalent layer magnetizations model for Australia based on MAGSAT data, Earth Planet. Sci. Lett., 83, 167-174, 1987.

Mayhew, M. A., and J. L. LaBrecque, Crustal geologic studies with MAGSAT and surface magnetic data, Rev. Geophys., 25, 971-981, 1987.

Mayhew, M. A., B. D. Johnson, and P. J. Wasilewski, A review of problems and progress in studies of satellite magnetic anomalies, $J$. Geophys. Res., 90B, 2511-2522, 1985.

Mayhew, M. A., P. J. Wasilewski, and B. D. Johnson, Crustal magnetization and temperature at depth beneath the Yilgam block, Western Australia inferred from MAGSAT data, Earth Plonet Sci. Lett., 107, 515-522, 1991.

Mutton, A. J., and R. D. Shaw, Physical property measurements as an aid to magnetic interpretation in basement terrains, Bull. Aust. Soc. Explor. Geophys., 10, 79-91, 1979.

Nagata, T., Magnetic susceptibility of compressed rocks, J. Geomagn. Geoelectr., 18, 73-80, 1966

Nagata, T., Basic magnetic properties of rocks under the effect of mechanical stresses, Tectonophysics, 9, 167-195, 1970.

Nagata, T., and B. J. Carleton, Notes on piezo-remanent magnetization of igneous rocks, J. Geomagn. Geoelectr., 21, 427-445, 1969.

O'Reilly, S. Y., and W. L. Griffin, A xenolith-derived geotherm for southeastern Australia and its geophysical implications, Tectonophysics, $111,41-63,1985$.

Parry, L. G., The influence of fine structures on the remanence of multidomain particles of magnetite and titanomagnetite, Phys. Earth Planet. Inter., 26, 63-71, 1981.

Percival, J. A., High-grade metamorphism in the Chapleau-Foleyet area, Ontario, Am. Mineral., 68, 667-686, 1983.
Percival, J. A., Granulite terranes and the lower crust of the Superior Province, in Properties and Processes of Earth's Lower Crust, Geophys. Monogr. Ser., vol. 51, edited by R. F. Mereu, S. Mueller, and D. M. Fountain, pp. 301-310, AGU, Washington, D.C., 1989.

Pozzi, J. P., Magnetic properties of oceanic basalts-effects of pressure and consequences for the interpretation of anomalies, Earth Planet. Sci. Lett., 26, 337-344, 1975.

Rochette, P., G. Fillion, J.-L. Mattéi, and M. J. Dekkers, Magnetic transition at 30-34 Kelvin in pyrrhotite: Insight into a widespread occurrence of this mineral in rocks, Earth Planet. Sci. Lett., 98, 319$328,1990$.

Samara, G. A., and A. A. Giardini, Effect of pressure on the Néel temperature of magnetite, Phys. Rev., 186, 577-580, 1969.

Schlinger, C. M., Magnetization of lower crust and interpretation of regional magnetic anomalies: Example from Lofoten and Vesteralen, Norway, J. Geophys. Res., 90, 11,484-11,504, 1985.

Schult, A., Effect of pressure of the Curie temperature of titanomagnetites $\left[(1-\mathrm{x}) \cdot \mathrm{Fe}_{3} \mathrm{O}_{4}-\mathrm{x} \cdot \mathrm{TiFe}_{2} \mathrm{O}_{4}\right]$, Earth Planet. Sci. Lett., 10, 81-86, 1970.

Shaw, R. D., Basin uplift and basin subsidence in Central Australia, Ph.D., Aust. Natl. Univ., Canberra, 1987.

Shaw, R. S., and L. P. Black, The history and tectonic implications of the Redbank Thrust Zone, Central Australia, based on structural, metamorphic and Rb-Sr isotopic evidence, Aust. J. Earth Sci., 38, 307 332, 1991.

Shaw, R. D., A. J. Stewart, and L. P. Black, The Arunta Inlier: a complex ensialic mobile belt in Central Australia, Part 2, Tectonic history, Aust. J. Earth Sci., 31, 457-484, 1984.

Shaw, R. D., B. R. Goleby, R. J. Korsch, and C. Wright, Basement and cover thrust tectonics in Australia based on the Arunta-Amadeus seismic-reflection profile, Basement Tectonics, 9, 55-84, 1992.

Shive, P. N., Can remanent magnetization in the deep crust contribute to long wavelength magnetic anomalies?, Geophys. Res. Lett., 16, 89-92 1989.

Shive, P. N., and D. M. Fountain, Magnetic mineralogy in an Archean crustal section: Implications for crustal magnetization, J. Geophys. Res., 93B, 12,177-12,186, 1988.

Sporer, $H$., On viscous remanent magnetization of synthetic multidomain magnetite, Geophys. Res. Lett., 11, 209-212, 1984.

Stacey, F. D., and S. K. Banerjee, The Physical Principles of Rock Magnetism, 195 pp., Elsevier, New York, 1974.

Stewart, A. J., R. D. Shaw, and L. P. Black, The Arunta Inlier: a complex ensialic mobile belt in Australia, Part 1, Stratigraphy, comelations and origin, Aust. J. Earth Sci., 31, 445-455, 1984.

Teyssier, C., A crustal thrust system in an intracratonic tectonic environment, J. Struct. Geol., 7, 689-700, 1985.

Teyssier, C., C. Amri, and B. E. Hobbs, South Arunta Block: The intemal zone of a Proterozoic overthrust in Australia, Precambrian Res., 40/41, 543-564, 1988.

Thomas, H. H., A model of ocean basin crustal magnetization appropriate for satellite elevation anomalies, J. Geophys. Res., 92B, $11,609-11,613,1987$

Toft, P. B., and S. E. Haggerty, A remanent and induced magnetization model of MAGSAT vector anomalies over the West African Craton, Geophys. Res. Lett., 13, 341-344, 1986.

Toft, P. B., and S. E. Haggerty, Limiting depth of magnetization in cratonic lithosphere, Geophys. Res. Lett., 15, 530-533, 1988.

Vernon, R., Metamorphic Process: Reactions and Microstructure Development, 247 pp. John Wiley, New York, 1975.

Wasilewski, P. J., and M. A. Mayhew, Crustal xenolith magnetic properties and long wavelength anomaly source requirements, Geophys. Res. Lett., 9, 329-332, 1982.

Wasilewski, P. J., and M. A. Mayhew, The Moho as a magnetic boundary revisited, Geophys Res. Lett., 19, 2259-2262, 1992.

Wasilewski, P. J., and R. D. Wamer, Magnetic petrology of deep crustal rocks-Ivrea Zone, Italy, Earth Planet. Sci. Lett., 87, 347-361, 1988.

Wasilewski, P. J., H. H. Thomas, and M. A. Mayhew, The Moho as a magnetic boundary, Geophys. Res. Lett., 6, 541-544, 1979.

Wellman, P., Gravity evidence for abrupt changes in mean crustal density at the junctions of Australian crustal blocks, BMR J. Aust. Geol. Geophys., 3, 153-162, 1978.

Williams, M. C., P. N. Shive, D. M. Fountain, and R. B. Frost, Magnetic properties of exposed deep crustal rocks from the Superior Province of Manitoba, Earth Planet. Sci. Lett., 76, 176-184, 1985

Worm, H.-U., Comment on "Can remanent magnetization in the deep crust contribute to long-wavelength magnetic anomalies?" by P. N. Shive, Geophys. Res. Lett., 16, 595-597, 1989. 
S. K. Banerjee and C. Teyssier, Institute for Rock Magnetism, Department of Geology and Geophysics, University of Minnesota, 293 Shepherd Laboratories, 100 Union Street SE, Minneapolis, MN 55455.

P. Kelso Department of Computer, Geological and Mathematical
Sciences, Lake Superior State University, Sault Ste. Marie, MI 49783.

Received November 20, 1992;

revised April 21, 1993;

accepted April 27, 1993.) 